\title{
RECICLANDO PRÁTICAS E SABERES CONTEMPORÂNEOS: A RECICLAGEM COMO UMA FORMA DE REINSERÇÃO SOCIAL E PROMOÇÃO DE UMA ECO-CIDADANIA
}

\author{
Mauro Meirelles ${ }^{1}$ \\ Daiane Schwengber ${ }^{2}$ \\ Luciana Hoppe ${ }^{3}$ \\ Simone Sperhacke ${ }^{4}$
}

Resumo: O presente artigo aborda a questão da reciclagem de lixo, focando-se na figura dos catadores e seu papel enquanto promotora de melhoria da qualidade ambiental. Discorre sobre o tema da eco-cidadania, da psicologia do compromisso e do desenvolvimento de valores democráticos. Além disso, aborda os catadores, seu trabalho, renda e cidadania, a partir de uma perspectiva histórica. Desta forma, discute-se no decorrer do texto a atividade de reciclagem num contexto de promoção de uma eco-cidadania. Nesse sentido, a partir de uma ação desenvolvida com 15 catadoras de cinco cooperativas da Região Metropolitana de Porto Alegre, que se focava na promoção de sua autoestima e empoderamento, busca-se colocar em evidência a importância da educação enquanto um elemento promotor de emancipação e promoção da cidadania.

Palavras-Chave: Educação. Cidadania. Eco-Cidadania. Reciclagem. Catadores.

Doutor em Antropologia e Pós-Doutorando em Ciências Sociais da Unisinos.

2 Mestre em Avaliação de Impactos Ambientais e Doutoranda em Memória Social e Bens Culturais do Unilasalle.

3 Mestre em Administração e professora da Uniritter.

4 Mestre em Design e Tecnologia e Doutoranda em Design da UFRGS. 


\section{INTRODUÇÃO}

A cada dia, mais e mais pessoas, (re)descobrem seus direitos e encontram no trabalho uma forma de retomar a sua dignidade e a perspectiva de um futuro melhor. Neste sentido, o que se observa é que muitas pessoas a partir da educação, têm buscado transformar a vida de outras pessoas. Num mundo onde apenas o capital e o lucro são tidos como pilares do desenvolvimento, a dimensão humana é muitas vezes esquecida.

Nesta busca incessante pelo lucro e pelo aumento da mais-valia absoluta o meio ambiente é deixado de lado e a busca de soluções mais ecológicas e/ou eco sustentáveis é vista como um empecilho no caminho do desenvolvimento. E, pouco ou nada se tem pensado em termos de o que fazer com as toneladas de lixo que são produzidas diariamente em nossas cidades.

Lixo esse que é muitas vezes largado diretamente nos lixões sem nenhuma triagem ou tratamento e que muitas vezes pode acabar por poluir os mananciais de água e o próprio lençol freático, como muito bem aponta Possamai et al. (2007), ao se referir aos lixões existentes na antiga região carbonífera do Santa Catarina, de modo que o lixo, como muito bem registram Santos e Rigotto (2008), se transforma num grande passivo ambiental com o qual as municipalidades têm que lidar.

Neste sentido, o que se observou a partir da segunda metade do século passado é que o processo de urbanização, o desenvolvimento industrial e o crescimento populacional tiveram um forte impacto ambiental, implicando, principalmente, num aumento exponencial da produção de resíduos sólidos urbanos em todas as regiões do planeta (DEMAJOROVIC; LIMA, 2013). E, enquanto uns aumentavam seus lucros com o desenvolvimento de tecnologias que garantiam um aumento da produção a partir do uso de novos materiais e embalagens, por exemplo, sem a mínima preocupação com o seu descarte posterior, outros extraem desses resíduos seu sustento.

Isto posto, e indo um pouco além, tem-se que a preocupação em torno de questões ambientais faz parte da agenda das mais diversas instituições, estando presente tanto no discurso de grande parte da atual classe política mundial, onde cada vez mais ganham espaço os chamados partidos verdes, quanto entre um sem número de ativistas e Organizações Não-Governamentais e do Terceiro Setor. Instituições essas que buscam cada vez mais espaço para levar adiante seu ideário, mas também, entre muitos setores da economia que veem a questão ambiental como uma forma de agregar valor a seus produtos, processos e serviços. 
Neste sentido, o que se observa é que, nos últimos cinquenta anos, houve um melhor entendimento acerca da questão ambiental, da necessidade de se tratar os resíduos industriais e de se pensar políticas de controle da poluição. Algo que, de certa forma, passa a dar tangibilidade à questão ambiental no sentido de pensar o meio ambiente como um patrimônio a ser preservado, como já escrevemos em outro lugar (MEIRELLES; PEDDE, 2014). Sobretudo, sobre essa ótica, tem-se que o princípio de uso de tecnologias limpas representa uma mudança paradigmática de grande envergadura, à esteira do proposto por Thomas Kuhn (1997), de modo que, a implementação destas tecnologias está orientada "ao que fazer para não se gerar resíduos" e não mais a questão orientadora do antigo paradigma que se ocupava de "o que fazer com os resíduos gerados".

Isso representou em termos práticos uma profunda mudança de perspectiva, de modo que aquilo que antes era visto como um problema e algo que somente gerava custos às empresas, também passou a ser visto como uma oportunidade de se pensar os processos produtivos e de melhorá-los ao ponto de se ganhar dinheiro com isso. Mas como assim? Por meio dos chamados créditos de carbono, por exemplo, através dos quais os países desenvolvidos que são os maiores emissores de gases do Efeito Estufa - compram certificações na forma de investimentos em projetos e processos de desenvolvimento de Mecanismos de Desenvolvimento Limpo (MDL). O que se constitui, segundo Antonio et al. (2012), em uma das ferramentas que colaboram para que os países desenvolvidos atinjam as metas de emissões estabelecidas no Protocolo de Quioto. Tais certificados dão direito aos países desenvolvidos de emitir gases do Efeito Estufa na medida em que estes também financiem projetos de MDL que visam a redução de Gases do Efeito Estufa (GEE). Fundamentalmente, tais créditos têm o objetivo de

alertar os países de que os processos industriais que agem de forma poluidora devem ser revistos no sentido de conciliar o desenvolvimento socioeconômico e a necessidade de diminuição de emissão dos GEE, buscando compensar as emissões através de um programa que desperte a vontade política de cada país em rever os seus processos industriais, e assim diminuir a poluição e o seu impacto no clima, através da compensação de emissões atmosféricas na medida em que proporcionam o equilíbrio entre as novas emissões de poluentes no ar e a sua redução. (ANTONIO et al., 2012, p. 8)

Ou ainda, esses certificados agregam valor à marca em função de uma infinidade de selos ambientais, padrões de produção e qualidade tidos como 
menos agressivos ao meio ambiente. Neste caso, nos referimos a processos produtivos tidos como mais limpos e menos agressivos ao meio ambiente, sobretudo, no que tange à aplicação de um conjunto de estratégias técnicas que, aplicadas a processos e produtos, têm a finalidade de aumentar a eficiência no uso de matérias-primas e outros insumos correlatos necessários a sua produção, tais como água e energia, de forma que, a partir de sua aplicação, reduza-se e/ou minimize-se a geração de resíduos e que são, na maioria das vezes, despejados no meio ambiente, seja no ar, na terra ou nos cursos d'água.

Neste sentido, podemos dizer que existem duas abordagens e/ou modos de pensar, na atualidade, a questão de geração de resíduos: a tradicional e a lógica. A tradicional, tida como a mais simples, tem o objetivo de incidir apenas na solução do problema de geração de resíduos sem, contudo, questionar o próprio processo de produção deste. Na maioria das vezes, representa um aumento significativo de custo quando associado ao gerenciamento destes resíduos, na medida em que tem seu foco somente no tratamento destes resíduos tornandose, a longo prazo, mais cara por agregar custo ao processo produtivo em si com a expansão da cadeia de produção e tratamento dos resíduos derivados do próprio processo.

Já a abordagem lógica tem como foco o desenvolvimento de soluções ligadas à prevenção e minimização de geração de resíduos a partir da implementação de processos mais eco-eficientes. Sua eficácia é bem maior na medida em que pressupõe mudanças no processo produtivo. E, também, mais complexa, uma vez que envolve a implementação e o desenvolvimento de novas tecnologias produtivas. Apesar de possuir um custo mais elevado a curto prazo, a longo prazo se torna barata na medida em que implica na redução permanente dos resíduos gerados. Na prática tem-se que a implantação de Programas de Produção Mais Limpa (PPML) exige um profundo conhecimento dos sistemas de produção industrial adotados e o monitoramento e a manutenção constante de processos no interior de sistemas produtivos mais eco-eficientes.

Entre os benefícios da implementação dos PPML está a identificação e a eliminação do desperdício, a minimização e a eliminação (ou mesmo a redução) do uso de matérias-primas, resíduos e emissões tidas como agressivas e/ou potencialmente perigosas ao meio ambiente, a redução dos custos no tratamento de resíduos e efluentes industriais e do passivo destinado ao seu tratamento. Tudo isso contribui para uma melhor imagem da empresa/marca no mercado, no aumento da produtividade através da otimização de processos, 
etc.

Outrossim, devemos lembrar que processos produtivos ligados aos PPML devem primar pelo desenvolvimento de um circuito fechado de produção que não contamine o meio ambiente e que, ainda, utilize os recursos naturais com a máxima eficiência possível como preconizam as modernas teorias da administração. Desta feita, tem-se que, quando reduzimos a emissão de poluentes e/ou resíduos para o meio ambiente, estamos também ajudando a preservar o meio ambiente na medida em que otimizamos o uso de matériaprima, recursos naturais e energia.

Isto posto, nos itens seguintes centraremos nosso foco em duas questões específicas. Uma primeira relaciona-se ao tratamento dos resíduos sólidos oriundos de matrizes industriais tradicionais, que encontram um destino mais ecologicamente sustentável a partir do trabalho de catadores e recicladores que têm nos galpões de reciclagem uma fonte de trabalho e renda. E, outra, voltada para a construção de novos valores e para a promoção de um modo e estilo de vida mais sustentável a partir do descarte consciente dos resíduos sólidos e seu encaminhamento aos galpões de reciclagem.

\section{ECO-CIDADANIA, PSICOLOGIA DO COMPROMISSO E DESENVOLVIMENTO DE VALORES DEMOCRÁTICOS}

São tidos como valores democráticos bastante valorizados no Brasil o ato de votar, o respeito às leis, o socorro a uma vítima de acidente, o uso racional dos recursos naturais, o descarte correto do lixo, a possibilidade de intervir/impedir que um roubo e/ou outro qualquer ato ilícito seja cometido, etc. Também, quando se fala em cidadania e valores democráticos, são muitas as referências feitas para a necessidade premente de se promover uma mudança de comportamento e de mentalidade e que a informação e o acesso a ela é um dos melhores caminhos a serem seguidos quando se pensa no desenvolvimento de ações pedagógicas que visem incidir positivamente sobre a realidade social (JOULE; BERNARD, 2005). Neste sentido,

Se assim se procede é porque se supõe que esta modificação de ideias ou de valores vai ser acompanhada por uma modificação efetiva dos comportamentos. A maioria das grandes campanhas de comunicação, bem como as lições de moral ou de instrução cívica assentam-se sobre este pressuposto. (JOULE; BERNARD, 2005, p. 27) 
Contudo, isso não é suficiente. Na medida em que,

Um cuidadoso estudo longitudinal, realizado há alguns anos nos Estados Unidos [...], mostrou que a probabilidade de ser um fumante aos 17 anos não é menor entre os alunos que frequentaram pelo menos 65 sessões de "sensibilização" entre oito e 17 anos (condição experimental) - e, portanto, perfeitamente informados dos prejuízos do tabaco - que nos alunos que não seguiram estas sessões (condição controle). (JOULE; BERNARD, 2005, p. 27)

Em razão disso, tem-se que a informação e o conhecimento sobre determinados fatos/acontecimentos/processos serve para modificar saberes e permite, na maioria dos casos, por parte de determinados sujeitos historicamente situados, uma tomada real de consciência acerca de determinada questão. Contudo, tal tomada de consciência não implica, necessariamente, que há uma mudança de atitude vinculada.

Por exemplo, todos sabemos que o plástico leva muito tempo para se decompor quando largado diretamente no meio ambiente e que as pilhas e baterias são ricas em metais pesados e tóxicos que podem facilmente contaminar o solo. Contudo, apesar de quase todos os grandes centros urbanos terem a coleta seletiva implementada, com vistas ao reaproveitamento do plástico, do vidro, do papel, dos metais etc., são poucas as pessoas que separam o seu lixo e o encaminham para a coleta seletiva. O mesmo acontece em relação às baterias e pilhas que, apesar de existirem os pontos para sua coleta em todas as cidades, estas acabam, na maioria dos casos, no lixo comum, que vai para os aterros sanitários.

Muitas são as justificativas que envolvem o descarte incorreto desse tipo de resíduo por parte dos cidadãos. Justificativas essas que vão desde o trabalho de separar o lixo, passam pela frequência com que a coleta seletiva é feita e acabam na necessidade de ter que se deslocar até um lugar específico para o correto descarte de pilhas e baterias, apesar de irmos ao supermercado toda a semana e nestes haver caixas coletoras. O que falta, grosso modo, segundo Joule e Bernard (2005) é o estabelecimento de um compromisso, um vínculo entre aquilo que se pensa e aquilo que se faz.

\section{A FIGURA DO CATADOR: TRABALHO, RENDA E CIDADANIA}

A figura do catador já era relatada através dos "garrafeiros", presentes nos bairros e vilas das cidades no começo do século XX (PINHEL, 2013). Com o 
passar dos anos e com o crescimento das cidades, outras pessoas iniciaram o processo de "catação" nas ruas para venda de papel e de sucata. Mais recentemente, temos os produtos descartáveis, que possuem vida curta no ciclo de consumo capitalista, de modo que representam hoje um dos maiores problemas ambientais urbanos e, consequentemente, um dos maiores produtos de venda para os catadores (DEMAJOROVIC; LIMA, 2013): as latinhas de alumínio e os vasilhames de plástico.

Historicamente, tem-se que a trajetória organizacional dos catadores remonta ao início nos anos 80, com o Movimento Comunidade dos Sofredores de Rua. Foi um evento realizado na cidade de São Paulo que convidou para participar as primeiras associações de catadores de papel e papelão, a COOPAMARE, primeira cooperativa de reciclagem do Brasil, e catadores individuais.

A partir dos anos de 1990, outros atores entraram em cena, de modo que um sem número de organizações não-governamentais, instituições sociais, incubadoras e poder público iniciaram campanhas de inclusão social e econômica de catadores. Movimento que culminou na implementação da coleta seletiva em diversos municípios, fazendo com que catadores individuais pudessem formar associações e cooperativas para a prestação de serviços (PINHEL, 2013).

Em 1998, o Fórum Nacional do Lixo e Cidadania debateu a conscientização sobre o trabalho, a busca pela organização e a construção de parcerias em Brasília. No primeiro Encontro Nacional de Catadores de Papel e Material Reaproveitável, que ocorreu em 1999, na cidade de Belo Horizonte, criou-se oficialmente o Movimento Nacional dos Catadores de Materiais Recicláveis (COSTA, 2008).

Já o movimento pelo reconhecimento do catador como um profissional que presta um serviço iniciou em Brasília, a partir do I Congresso Nacional dos Catadores de Materiais Recicláveis realizado em 2001. Este evento reuniu mais de 1.700 profissionais que atuavam nas ruas das cidades, lixões, associações e cooperativas de reciclagem e que resultou, pela primeira vez, na construção de um documento oficial.

De acordo com o Movimento Nacional dos Catadores de Materiais Recicláveis, a maior conquista, no decorrer do processo de organização, foi interna. Isso porque, do ponto de vista da cidadania e do fomento a valores democráticos, passaram a pensar e trabalhar pela mobilização e união da categoria de modo que, como o passar dos anos, passou-se a perceber a figura 
do catador não como concorrente, mas como um companheiro, que deveria ser incorporado ao rol de profissionais que trabalham com a reciclagem de materiais.

Anteriormente à inserção do catador como profissional, Ferreira e Anjos (2001) descreviam o perfil de catadores subdivididos em três categorias: catadores de rua, catadores cooperados e catadores de lixão. Denomina-se catador de rua a categoria que coleta em sacos de lixo colocados na rua pela população, pelo comércio local ou pelas indústrias, tendo sua própria carroça ou qualquer outro transporte adaptado para carga. Os catadores cooperativados e autogestionários são aqueles que prestam o serviço de coleta seletiva de qualidade, de forma articulada e organizada, gerando trabalho e renda. Os catadores de lixão, por sua vez, seriam aqueles que estão à margem do sistema e em maior condição de vulnerabilidade social, na medida em que fazem a catação diretamente nos lixões dos municípios e não estão vinculados a nenhum grupo e/ou organização (FERREIRA; ANJOS, 2001).

Outra tipologia, utilizada por Gonçalves (2003) descreve os diferentes tipos de catadores no Brasil dividindo-os em: trecheiros, catadores de lixão, catadores individuais e catadores organizados. Os trecheiros são aqueles que vivem de cidade em cidade, sem residência fixa, e catam latas de alumínio ou papelões para a venda diária. Os catadores de lixão, que catam de dia ou de noite nos lixões a céu aberto, fazem seu horário e catam há muito tempo ou só quando estão sem serviço de obra, pintura, etc. Podem ser também catadores individuais e/ou estarem organizados em cooperativas/associações, geralmente morando próximo ao próprio lixão, em condições insalubres.

Os catadores individuais, como o nome indica, catam por si e preferem trabalhar de modo independente, puxando carrinhos muitas vezes emprestados pelo comprador, que é o sucateiro. E, por fim, temos os chamados catadores organizados, em cooperativas ou associações que, geralmente, têm sua origem na união de um certo número de catadores individuais que passam a trabalhar de modo mais sistemático e organizado.

Sobremaneira, tem-se que a regulamentação da profissão de catador somente se deu em 2002, quando a profissão foi inserida na Classificação Brasileira de Ocupações (CBO94). Conquista essa que implicou no resgate da dignidade desses trabalhadores, inserindo-os no âmbito das políticas públicas. Neste sentido, tem-se que a Classificação Brasileira de Ocupações (BRASIL, 2010) identifica pelo número 5192 os tipos de trabalhadores da coleta e seleção de material reciclável, categorizando-os em três subdivisões: catador de material 
reciclável, selecionador de material reciclável e operador de prensa de material reciclável.

É considerado catador de material reciclável todo catador de ferro-velho, papel e papelão, sucata, vasilhames de plástico ou de vidro e enfardador de sucata, com trabalho realizado em cooperativas ou associações. Mas há também os catadores individuais e os sucateiros. Os catadores individuais vendem os materiais coletados para associações, cooperativas ou sucatões. Geralmente, escolhem o melhor preço, sem vínculos pessoais ou profissionais. Os sucateiros agem como pequenos empresários, sem nenhuma relação com os movimentos cooperativistas ou de economia solidária (BRASIL, 2010).

O selecionador de material reciclável é a categoria de catadores que separa os materiais recicláveis, as sucatas. Pode também ser denominado de triador de material reciclável e/ou de sucata. Segundo a Classificação Brasileira de Ocupações (BRASIL, 2010), cabe a este grupo de trabalhadores as seguintes responsabilidades: preparar o material para a expedição, operar o triturador e realizar a manutenção do ambiente e de equipamentos de trabalho, fabricar e fazer a manutenção de carrinhos e/ou carroças, tratar os animais quando for o caso, limpar as instalações da cooperativa ou associação, limpar os recipientes e locais de coleta, a prensa, a balança e lubrificar e realizar pequenos reparos nos equipamentos. E a última subdivisão é a de operador de prensa de material reciclável, reconhecido como enfardador de material de sucata, prenseiro ou prensista (BRASIL, 2010).

Neste sentido, tem-se que a profissão catador vem se fortalecendo, ocupando espaço nos fóruns, discussões e junto ao poder público. Porém, continua sendo desvalorizada pela sociedade e é associada, muitas vezes, à falta de interesse por parte do catador em buscar um trabalho formal, ou ainda, devido à falta de escolaridade, não é visto como profissional prestador de um serviço de grande importância ambiental (MIURA, 2004).

Atualmente, uma maneira de o catador conseguir seu espaço de trabalho é através da formação de cooperativas de reciclagem, de modo que ações que eram realizadas individualmente, agora são realizadas coletivamente. Com isso, obtêm-se melhores preços no momento da comercialização do material reciclável por eles coletado e triado (CARVALHO, 2008). Grosso modo, podese dizer que, de uma maneira geral, as cooperativas de reciclagem, quando apoiadas pelo poder público ou por entidades, sejam universitárias ou do movimento político emancipatório, trabalham com base na economia solidária, que tem como um dos seus principais valores a autogestão. 
A autogestão se caracteriza por ser um modelo que se pauta na gestão compartilhada e democrática, onde todos participam das decisões e buscam o bem comum para a cooperativa e para seus cooperativados (SINGER, 2002). O principal objetivo das cooperativas fundadas nestes moldes reside na possibilidade de se gerar trabalho, renda e melhores condições de vida a uma parcela excluída da população.

\section{A ATMIDADE DE RECICLAGEM COMO PROMOTORA DE UMA ECO-CIDADANIA}

A partir de uma perspectiva sistêmica (EASTON, 1968) tem-se que toda transformação social passa, obrigatoriamente por uma mudança de paradigma. Nesse sentido, se quisermos entender o funcionamento de um sistema social qualquer é preciso que pensemos esse sistema em termos de entradas (inputs) e saídas (outputs), de modo que possamos conhecer e explorar as funções que cada microssistema tem sobre o todo. Nesse sentido, como escrevem De Gregori e De Gregori (2011, p. 11):

A formação e o fomento de cadeias de produção em equilíbrio com a natureza e inseridas em um contexto social onde existe uma sabedoria passada de geração em geração iria não só possibilitar a independência econômica e cultural desses povos, como também desenvolver um método produtivo altamente renovável na medida em que, quanto maior a biodiversidade, maior a capacidade de regeneração dos ecossistemas. Dessa forma, além de produzir de uma maneira sustentável, essas "empresas" tradicionais poderiam inclusive se apresentar como competitivas no mercado internacional. Não no sentido de distribuírem seus produtos em todo globo, evidentemente, mas porque ninguém teria a capacidade de competir com elas no local onde estão instaladas.

Nesse contexto, a atividade de reciclagem coaduna com esse movimento e a perspectiva de uma mudança estrutural na atual dinâmica da produção e consumo com a reinserção de resíduos produzidos a partir de cadeias abertas de produção, novamente, no interior do sistema produtivo, de modo que cadeias produtivas que até então eram tidas como abertas passam a ser fechadas num círculo virtuoso.

Nesse processo de reintrodução e reutilização de resíduos tidos como recicláveis e capazes de serem reintroduzidos no interior do sistema produtivo a partir de pequenos ajustes e mudanças no ciclo produção, novos valores e formas de pensar a relação com o meio ambiente são gestadas. Assim, quando a 
sociedade começa a ver o ser humano pela óptica capitalista, do lucro, e aqueles que não conseguem corresponder a essa concepção se encontram à margem do progresso e sem uma utilidade, há um processo de "coisificação do homem" de modo que aqueles que encontram-se fora desse sistema são desvalorizados.

Nesse sentido, a partir da perspectiva de Paulo Freire (2003) e de trabalho realizado com 15 mulheres de 5 cooperativas da Região Metropolitana de Porto Alegre, no item seguinte nos ocuparemos do relato dessa experiência e do modo como, a partir de um simples curso de diç̧ão e oratória promovido com estas, houve um processo de empoderamento das mulheres catadoras gerando uma mudança de perspectiva em relação ao seu trabalho e ao modo como elas se inserem no interior do sistema, por meio de um processo de tomada de consciência de sua condição histórica e da importância do trabalho que realizam no interior das cooperativas das quais fazem parte.

A falta de reflexão em relação ao resíduo sólido gerado diariamente pelos cidadãos é, grosso modo, um dos fatores que ensejam certa desvalorização do profissional catador. Contudo, quando por algum motivo, seja por falta de educação e cidadania da população, seja pela desorganização do poder público, ocorrem desastres ambientais, tais como enchentes, ou ainda, há o acúmulo de resíduos sólidos na frente das casas, que entopem bueiros e/ou ficam dispostos a céu aberto em vias públicas, se percebe a necessidade da coleta seletiva e do trabalho realizado pelos catadores.

\section{A EDUCAÇÃO COMO ELEMENTO DE EMANCIPAÇÃO E PROMOÇÃO DA CIDADANIA}

Neste item relataremos a experiência de um curso de dicção e desinibição, ministrado por nós, junto a um conjunto de 15 mulheres catadoras de material reciclável que atuam em 5 cooperativas do Rio Grande do Sul. O curso teve duração de 16 horas e foi dividido em 4 encontros com duração de 4 horas cada. Os encontros foram feitos em ambiente de sala de aula, com a disposição das cadeiras em forma de "U". As apresentações feitas em slides e os materiais utilizados nos encontros basearam-se quase que exclusivamente no uso de imagens, dada a baixa escolaridade do público-alvo e o fato de sabermos que boa parte das participantes era analfabeta ou possuía apenas o ensino fundamental.

Logo de início construiu-se, em conjunto com as mulheres participantes, um certo conjunto de regras que deveriam ser cumpridas com vistas ao bom 
andamento do curso. As regras não foram impostas, mas foram construídas a partir do diálogo e daquilo que elas consideravam importante pactuar para que todos obtivessem o máximo proveito do curso. Nesse sentido, ao final de cerca de 40 minutos, ficou estabelecido uma pacto pedagógico que devia ser observado por todos e que incluía aquilo que elas consideravam como mais importante para o bom andamento dos trabalhos. Desta feita, tem-se que, $a$ priori, ficou estabelecido em nosso pacto pedagógico que:

1) Todos deveriam respeitar os horários previstos, tanto de chegada quanto de saída, assim como os intervalos. Também ficou estabelecido que exceções poderiam ser feitas, mas que essas deviam ser discutidas com o grupo;

2) Na medida do possível, todos deveriam se focar no curso e se esforçar para manter a atenção nas atividades, evitando conversas paralelas e/ou outras atividades que não tivessem relação com aquilo que estava sendo desenvolvido no curso;

3) A opinião de todos deveria ser respeitada, todos teriam voz e que, cada contribuição deveria ser feita a seu tempo, de modo ordenado, aguardando a vez de falar e respeitando a fala dos outros;

4) Todas as falas e relatos seriam feitos em primeira pessoa uma vez que elas falariam e relatariam fatos de sua vida e cotidiano sendo, portanto, detentoras de um saber e um saber-fazer que lhe denota autoridade e conhecimento de causa;

5) Tudo aquilo que fosse discutido e relatado no curso deveriam ficar dentro da sala de aula, garantindo-se a confidencialidade e a liberdade de expressão visto que, certas falas, em outro contexto, não seriam bem-vistas por seus esposos/maridos e poderiam gerar certas sanções sociais, dado o machismo latente existente no interior das cooperativas e o fato destes não considerarem importante que "suas mulheres" sejam desinibidas e saibam falar bem; e,

6) Todos deveriam cooperar com os colegas/professores, deveriam participar das atividades e manter o foco nos encontros como se estivessem em suas cooperativas para que, a partir da colaboração de todas, se desinibissem e aprendessem a falar em público tranquilamente. 
Figura 1. Exemplo de lâmina utilizada em uma das apresentações feitas.

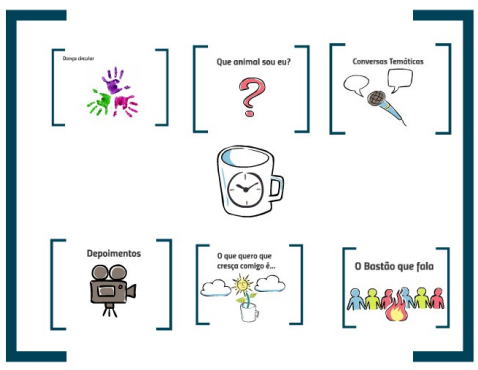

Fonte: os autores.

No mais, pode-se dizer, grosso modo, que tal dinâmica funcionou muito bem em todos os encontros, sendo raras as vezes que as regras tiveram que ser retomadas. Muitas vezes, foram retomadas pelas próprias catadoras, que diziam as colegas que uma outra colega estava falando e que, esta, deveria aguardar sua vez para dar sua contribuição. Dito isto, tem-se que cada aula pautou-se no uso de uma dinâmica específica e no cumprimento de determinados objetivos que, ao longo das aulas, implicariam no cumprimento daquilo a que o curso se propunha, qual seja, de ajudá-las a se comunicar melhor, aumentando assim a sua autoestima e confiança com vistas a uma tomada de consciência de si enquanto mulher, mãe, trabalhadora, catadora e cidadã.

Sendo assim, no desenvolver da primeira aula, iniciamos como a apresentação das professoras Luciana Hoppe e Simone Sperhacke, que efetivamente ministraram o curso. Foi solicitado ainda às participantes que formassem um círculo e que, em pé, se apresentassem ao grupo. Cada uma das participantes devia dizer seu nome e, em seguida, dizer uma palavra que rimasse com seu nome e remetesse a uma característica sua que gostaria de destacar.

Mais adiante, foram distribuídas entre as participantes algumas folhas de papel A3 e material de desenho. Solicitou-se então que fizessem um desenho com temática livre e, enquanto desenhavam, era tocada uma música incidental, baseada apenas no uso de instrumentos e sons, sem vozes. O que denotava um certo clima místico e de transformação interior. Outrossim, à medida que elas iam terminando seus desenhos, estes iam aos poucos sendo fixados na parede da sala de aula. Quando todas já haviam finalizado a atividade, foram 
convidadas a observar os desenhos feitos por suas colegas e, posteriormente, uma por uma explicou o seu desenho e o porquê da escolha do tema às outras.

Em seguida foi realizada uma dança circular cuja única exigência consistia em que as participantes deviam dançar olhando uma nos olhos da outra. E, novamente, foram distribuídas dentre as participantes outra folha A3, solicitando-lhes que fizessem um outro desenho, desta vez com temática definida: suas rotinas diárias. E, seguindo a mesma metodologia utilizada anteriormente, os desenhos foram fixados nas paredes da sala e uma a uma iam olhando o desenho das colegas e explicando suas rotinas.

Para encerrar esse encontro, sentaram-se em círculo e, de modo descontraído, cada uma foi dizendo uma palavra que resumia como elas estavam se sentindo naquele momento. Contudo, nem tudo foram flores, uma vez que, nesse encontro, em função das atividades propostas, ficou evidente a dificuldade que elas tinham para falar em público, caracterizada pela extrema timidez que demostraram desde as primeiras tarefas propostas. No encontro seguinte, as atividades foram realizadas de outro modo, à esteira do exposto por Freire (2003), a partir elementos que fazem parte de seu cotidiano.

Sendo assim, iniciamos o segundo encontro com um exercício de vocabulário chamado "Um som puxa o outro: na cozinha". Para iniciar, uma das professoras iniciou o exercício dizendo algo que tinha na cozinha de sua casa e solicitou à participante seguinte que dissesse outro objeto ou alimento que iniciasse com a letra final da que foi falada anteriormente (por exemplo: Geladeira - Avental; Avental - Laranja; etc.). Nesse sentido, optou-se por escolher um espaço de dentro de casa como tema central, por se tratar de ambiente com o qual todas as participantes estavam bem familiarizadas.

No momento seguinte, novamente, realizou-se outra dança circular similar à da aula anterior, agora, sem a exigência de olhar nos olhos, mas com vistas a tornar a aula mais descontraída e integrar mais o grupo. Agora, mais descontraídas, foi-lhes solicitado que retomassem suas rotinas da aula anterior e que, a partir de uma série de imagens pré-definidas pelas professoras e contidas num envelope pardo que, uma a uma, eram retiradas por cada uma delas, contassem, juntas, uma história, introduzindo nessa, sempre, o novo elemento retirado do envelope. 
Figura 2. Algumas imagens utilizadas nessa dinâmica.
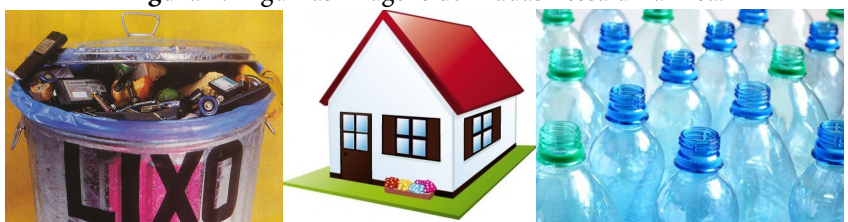

Fontes: www.vivaareal.com.br; www.youtube.com; www.metalica.com.br.

Com a finalidade de integrar ainda mais o grupo, além de abordar desenvoltura, respeito, criatividade, utilizou-se um exercício chamado "TocôColô". Quando estavam mais descontraídas, após alguns comandos que fazem parte da referida dinâmica, passou-se para a realização de outra atividade que consistia em contar, a exemplo da usada anteriormente, uma história, só que dessa vez com imagens que não remetiam ao cotidiano.

Feito isso, e bem mais desinibidas, era o momento de fazer com que elas falassem de si e, então, solicitou-se a elas que retirassem de suas bolsas um objeto que gostassem e que contassem ao grupo um pouco da história desse objeto e por que elas o consideravam importante. Este Momento evocou nelas sentimentos e sensações mais diversas que beiravam à catarse coletiva, na medida em que grande parte dos objetos remetia a sua vida pessoal, a sua família e ao seu trabalho na cooperativa.

Já no terceiro encontro, uma vez que já estavam mais à vontade enquanto grupo, optou-se por se utilizar outras dinâmicas. Então, foi realizado um exercício para ativar o cérebro e os reflexos, chamado "Um, Dois, Três", que envolve fala, expressão corporal e uso da motricidade fina. Em seguida, realizou-se uma outra atividade chamada de "Começo, Meio e Fim: uma forma de se organizar as ideias em pensamento antes de verbalizar", atividade essa que consistia na entrega de três cartas com imagens diversas a cada uma das participantes, de modo que estas deveriam unir as três imagens em uma única história, integrando as três imagens sorteadas.

O terceiro momento desse encontro consistiu no chamado "As Ilhas e o Tubarão". Nesse momento, foram colocados jornais abertos no chão com tamanhos diferentes que representavam ilhas. Então foi explicado aos participantes que eles deveriam imaginar que a sala representava o mar. E que, todas as vezes que a palavra TUBARÃO fosse mencionada, elas deveriam correr para uma ilha. Quem ficasse fora da ilha o tubarão devorava. A cada vez que apalavra tubarão era pronunciada, retirava-se um jornal ou parte dele. Isso foi 
feito até que as participantes ficassem bem unidas dentro de jornais. Por fim falou-se o que, alegoricamente, isso representava: o mar, as nossas vidas; as ilhas, a união; e, o tubarão o inimigo e/ou ameaça.

Outra atividade realizada nesse encontro, um pouco antes de encerrá-lo, foi a chamada de "Retrato Falado". Para realizar essa atividade, dada uma das participantes recebeu o nome de uma colega e foi informada que deveria descrevê-la sem, porém, falar de aspectos muito óbvios, como roupas, ou aspectos físicos. Mas que deveria focar-se em aspectos mais subjetivos de sua colega. Ao passo que, à medida que a colega ia falando, as outras deveriam, a partir da narrativa, descobrir de qual colega se tratava.

E, por fim, no quarto e último encontro, abriu-se as atividades com a chamada "Dança do Abraço", dinâmica essa que consistia na realização de alguns movimentos que sempre culminavam num abraço de uma colega. Ainda, nesse encontro, conversas temáticas foram realizadas e deixou-se que elas falassem à vontade, a partir de imagens que faziam referência ao seu cotidiano. Desta forma, gerou-se uma conversa livre, na qual as participantes puderam conversar sobre vários pontos relevantes de sua vida, como trabalho, família, entre outros.

A esse momento, seguiu-se uma rodada de depoimentos pessoais que, a partir da fala de uma outra líder de cooperativa que não pertencia ao grupo, eram instadas a pensar as dificuldades e desafios que tinham pela frente. Com vistas a dar maior tangibilidade à mudança que estavam trabalhando em si, foi lhes dado um copo plástico com terra e uma semente de girassol, a qual deveria plantar no referido copo. Este copo deveria levar consigo, juntamente com seus sonhos e desejos e lembrando sempre que a vida é feita de escolhas e se não cuidarmos do meio ambiente, de nossa aparência e dermos voz àquilo que queremos, podemos, como o girassol que morre a míngua se não receber água, acabarmos no esquecimento.

E, sabendo-se a partir de seus relatos, que nenhuma delas havia nunca comprado uma maquiagem e que apenas usavam aquilo que encontravam junto com o material que coletavam para reciclagem, optou-se por dar a elas no final do curso um batom. Um batom que representava o poder que tinham e a possibilidade de transformação de sua realidade, a partir de uma simples mudança de atitude e do ato de falar, de posicionar-se, de conhecer a si própria e aos outros, tornando-se assim uma cidadã plena de direitos e capaz de reivindicar a partir do uso da palavra. 


\section{CONSIDERAÇÕES FINAIS}

A partir desse breve relato de uma atividade realizada com 15 mulheres catadoras constatou-se que não é necessário que grandes investimentos sejam feitos com vistas ao desenvolvimento de valores democráticos. Mas que, antes disso, é necessário que se trabalhe com a autoestima desses trabalhadores que, no âmbito da sociedade em geral, são colocados à margem do sistema.

Também ficou evidente, a partir de seus relatos, a importância que seu trabalho e participação na cooperativa, e a relação que estes possuem com aquilo que nós denominamos de lixo e que, para elas, é tido como uma fonte de renda a partir de sua venda, e também, de matéria prima para produção de artesanato. Peças produzidas por elas, que decoraram a exposição fotográfica de lançamento do livro "Recicladores de histórias, catadores de sorrisos", de autoria de Daiana Schwengber, Jáder da Cruz Cardoso, Pedro Henrique Tesch, DelmarBizani, publicado no ano de 2015 pela Editora CirKula, realizado no dia 27 de novembro no Unilasalle Canoas.

Do ponto de vista da cidadania, o que se observa é que há entre elas um compromisso, não só de trabalho e renda, mas também com o meio ambiente, na medida em que, em muitas de suas falas, se faz presente a importância de separar o lixo e de reciclá-lo. Algo que, na esteira do exposto por Joule e Bernard (2005), nos remete ao estabelecimento de um compromisso, um vínculo entre aquilo que se pensa e aquilo que se faz.

\section{REFERÊNCIAS}

ANTONIO, A. C.; ANDRADE, B. C.; PAIVA, É. F.; FACCHINI, F. D.; SILVA, F. S.; SOUSA, G.H. Crédito de Carbono: investimento sustentável? FGV, 2012.

BRASIL. Ministério do Trabalho. Classificação Brasileira de Ocupações: CBO. Brasília: MTE, SPPE, 2010.

CARVAlHO, A. M. R. Cooperativa de Catadores de Materiais Recicláveis de Assis-COOCASSIS: Espaço de Trabalho e de sociabilidade e seus desdobramentos na consciência. 2008. 310 f. Tese (Doutorado em Psicologia) Instituto de psicologia da Universidade de São Paulo. São Paulo, 2008.

COSTA, C. M. Reciclagem e cidadania: a trajetória de vida dos catadores de material reciclável da comunidade Reciclo. 2008. 168 f. Dissertação (Mestrado em Educação) - Universidade de Brasília, Brasília, 2008. 
DE GREGORI, M. S.; DE GREGORI, I. C. S. Direitos da Sociobiodiversidade: a exploração dos conhecimentos tradicionais sob uma perspectiva de ecocidadania. Revista Eletrônica do Curso de Direito da UFSM, Santa Maria, v. 6, n. 2, pp. 1-15, 2011.

DEMAJOROVIC, J.; LIMA, M. Cadeia de reciclagem: um olhar para os catadores. São Paulo: Edições SESC SP, 2013.

EASTON, D. Uma teoria de análise política. Rio de Janeiro: Zahar, 1968.

FERREIRA J. A.; ANJOS L. A. Aspectos de saúde coletiva e ocupacional associados à gestão dos resíduos sólidos municipais. Cadernos de Saúde Pública, v.17, n.3, pp.689-696, 2001.

FREIRE, P. Pedagogia da esperança: um reencontro com a pedagogia do oprimido. São Paulo: Paz e Terra, 2003.

GONÇALVES, P. A reciclagem integradora dos aspectos ambientais, sociais e econômicos. Rio de Janeiro: DP\&A: Fase, 2003.

JOULE, R. V.; BERNARD, F. Por uma Nova Abordagem de Mudança Social: A Comunicação do Compromisso. Psicologia: Teoria e Pesquisa, v. 21, n. 1, pp. 27-32, 2005.

KUHN, T. S. A estrutura das revoluções científicas. São Paulo: Perspectiva, 1997.

MEIRELLES, M.; PEDDE, V. Ver, tocar, preservar: pensando a noção de patrimônio a partir de sua tangibilidade. Estudos de Sociologia, v. 1, p. 1-20, 2014.

MIURA, P. C. O. Tornar-se catador: uma análise psicossocial. Dissertação de Mestrado. Pontifícia Universidade de São Paulo, São Paulo, 2004.

MEIRELLES, M.; PEDDE, V.; FIGUEIREDO, J. A. S. A água enquanto um patrimônio tangível da humanidade: meio ambiente, patrimônio, educação e políticas públicas. In: MEIRELLES, M.; FIGUEIREDO, C. A. S.; SCHWEIG, G. R. Direitos Humanos e Sociais: Educação, Patrimônio e Meio Ambiente (Coleção Olhares Contemporâneos - Volume 1). Porto Alegre: CirKula, 2014. p. 219-242.

PINHEL, J. R. Do Lixo à Cidadania: Guia para Formação de Cooperativas de 
Catadores de Materiais Recicláveis. São Paulo: Editora Peirópolis, 2013.

POSSAMAI, F. P.; VIANA, E.; SCHUlZ, H. E.; COSTA, M. M.; CASAGRANDE, E. Lixões inativos na região carbonífera de Santa Catarina: análise dos riscos à saúde pública e ao meio ambiente. Ciência \& Saúde Coletiva, v. 12, n.1, pp. 171-179, 2007.

SANTOS, G. O.; RIGOTTO, R. M. Possíveis impactos sobre o ambiente e a saúde humana decorrentes dos lixões inativos de Fortaleza (CE). Revista Saúde e Ambiente, v. 9, n. 2, pp. 66-62, 2008.

SINGER, Paul. Economia Solidária: um modo de produção e distribuição. In: SINGER, Paul; SOUZA, André R. (Orgs.). A economia solidária no Brasil: a autogestão como resposta ao desemprego. São Paulo: Contexto, 2002.

\title{
Reciclando práticas y saberes contemporáneos: la reciclaje como una forma de reinserción social y promoción de uma eco-ciudadanía
}

\begin{abstract}
Resumen: En este artículo se aborda el concepto de reciclaje, centrándose en los colectores de basura y su rol como promotores de la mejora de la calidad ambiental. Se discute el tema del eco-ciudadanía, el compromiso psicológico y el desarrollo de los valores democráticos. Este artículo también tiene la intención de analizar (en una perspectiva histórica) el trabajo, los ingresos y también la ciudadanía de los recolectores de basura. De esta manera, se sostiene la actividad de reciclaje en un contexto de promoción del eco-ciudadanía. En este sentido, a partir de un programa desarrollado con 15 colectores de basura distribuidos em 5 cooperativas del área metropolitana de Porto Alegre, que se centra en la promoción de la autoestima y la autonomía, preténdese dar a conocer la importancia de la educación como un elemento de promoción del emancipación y la ciudadanía.
\end{abstract}

Palabras-clave: Educación. Ciudadanía. Eco-ciudadanía. Reciclaje. Colectores de basura. 
Recycling contemporary practices and knowledge: recycling as a form of social reinsertion and promotion of an eco-citizenship

\begin{abstract}
This article analyzes the concept of recycling, focusing on the trash collectors and their role as promoters of improving environmental quality. It discusses the theme of eco-citizenship, psychology and the development of democratic values. This article also intends to analyze (in a historical perspective) the work, the incomes and also the citizenship from those trash collectors. In this way, it is argued the recycling activity in a context of promoting eco-citizenship. In this sense, from a program developed with 15 collectors of five cooperatives in metropolitan area of Porto Alegre, which is focused on selfesteem promotion and empowerment, the study seeks to highlight the importance of education as an element to promote emancipation and citizenship.
\end{abstract}

Keywords: Education. Citizenship. Eco-Citizenship. Recycling. Trash collectors. 